\title{
UM ROMANCE PARANAENSE
}

\author{
Marilene Weinhardt ${ }^{*}$
}

nvestigação a respeito do material ficcional sobre o Contestado levoume a um romance que, pelo seu significado histórico e pelas características narrativas, não merece o desconhecimento em que jaz. ${ }^{1}$ Eles não acreditavam na morte, ${ }^{2}$ subintitulado "Romance dos tempos dos fanáticos do Contestado", de Frederecindo Marés de Souza, foi publicado postumamente, em 1978, mas é datado de vinte anos antes, portanto anterior a Casa Verde (1963), de Noel Nascimento, e Geração do deserto (1964), de Guido Wilmar Sassi, este sem dúvida ainda hoje a mais alta expressão literária sobre o tema. Recentemente, na promissora vertente da ficção histórica e no resgate efetivado com fins de maior divulgação e difusão desse movimento - já que parece que não seria o caso de se falar em revisão, uma vez que abordagens de cunho histórico-sociológico dos anos 60 já haviam operado a relativização da visão da história oficial, caso dos estudos de Maria Isaura Pereira de Queiroz, de Maurício Vinhas de Queiroz e de Duglas Teixeira Monteiro -, multiplicaramse os títulos ficcionais que exploram a temática do Contestado. ${ }^{3}$

- Universidade Federal do Paraná.

1 Este artigo reproduz parcialmente capítulo de um trabalho inédito que estuda vários tipos de discursos sobre a história do Contestado.

2 SOUZA, Frederencindo Marés de. Eles não acreditavam na morte. Curitiba: Instituto Histórico, Geográfico e Etnográfico Paranaense, 1978. As citações extraídas desta obra serão indicadas, no corpo do texto, pelas iniciais do título, seguidas do(s) número(s) da(s) página(s).

3 Refiro-me particularmente a Império caboclo (Movimento, 1994), de Donald Schüler; Os rebeldes brotam da terra (FTD, 1995), de Alcides Ribeiro J. da Silva; e O bruxo do Contestado (Nova Fronteira, 1996), de Godofredo de Oliveira Neto. 
Ainda que a publicação, relativamente recente, tenha sido uma homenagem do Instituto Histórico, Geográfico e Etnográfico do Paraná, que a edição esteja esgotada e que o nome da família seja bastante conhecido no Estado, tendo sido o autor um homem público, uma cortina de silêncio cerca a obra. Embora não se possa tomá-la como obra-prima, nem mesmo como obra literária medianamente realizada, o registro de outras obras de nível estético equivalente na história literária do Paraná torna injustificado esse silêncio. Como se verá na abordagem do texto, o autor dispõe de um mínimo de recursos narrativos, tem intimidade com o assunto e demonstra capacidade inventiva suficiente para merecer alguma atenção da crítica e dos historiadores da literatura. Tomando emprestada a conhecida expressão de Euclides da Cunha, parece que a consciência sobre os "crimes da nacionalidade" é perversa a ponto de não permitir que suas figurações atinjam proporções de atos culturais perturbadores.

Advogado, sempre respondendo por funções públicas junto ao governo do Estado, autor de uma única obra de ficção e de outra, também única, de caráter histórico-biográfico, cujo assunto está em estreita conexão com a ficcional - O presidente Carlos Cavalcanti e a Revolta do Contestado Frederecindo Marés de Souza, com Eles não acreditavam na morte, surpreende com alguns recursos ficcionais bem empregados e uma figuração dos fatos que antecipa certos traços ainda não corriqueiros no modo de se entender a história na época da escrita da obra.

Para explicar o lançamento tardio, não se pense em uma entusiasmada descoberta de algum crítico ou historiador da literatura, ou ainda de um editor. Trata-se de uma homenagem e parece não ter suscitado comentários de outro teor.

O volume, em edição de circulação restrita, traz uma "Explicação" do autor, datada de 1958. É evidente que uma obra só se realiza como tal no momento em que encontra seu leitor. Sem que se cumpra o circuito da comunicação, ela existe apenas em potencial. Ainda assim, comento o texto tendo em vista a perspectiva daquele ano. $O$ fato de levar em conta o momento em que o escritor considerou seu texto por terminado faz grande diferença, particularmente em relação ao romance histórico, que depende de pesquisa documental, e mais especialmente ainda quando se trata de assunto que posteriormente mereceu estudos revisionistas.

A frase que dá título ao romance é reveladora de vários aspectos. Em primeiro lugar, demonstra uma percepção pouco usual, na época, sobre a importância da fé para o movimento. Às razōes históricas e sociais para o surgimento e a duração da luta é preciso acrescentar a crença, elemento decisi- 
vo, talvez o único que explique a resistência tão absurda do ponto de vista considerado racional. Mas que crença poderia dar ao ser humano tanta força, tanta indiferença diante de ameaça tão forte à sua integridade física? Só libertando-se da maior maldição, do mais terrível segredo, da grande limitação humana, poderia o homem mostrar essa força. Liberto da morte, torna-se um pouco mais parecido com a divindade, toma para si um pouco da chama divina. Então pode tudo, pode enfrentar qualquer força, porque nada mais representa perigo.

Desde o título, o narrador marca a distância que o separa dos sertanejos. A posição do sujeito é ocupada pela terceira pessoa do plural, sublinhando a diferença. Ainda mais, é uma frase negativa. Não se reafirma a vida, mas a negação da morte, conservando o grande estigma na evocação da palavra. Ciente da força desse título, o narrador retoma-o, com pequenas variações, em cabalísticas três passagens. A primeira está na descrição do momento da morte de José Maria: "Ele não acreditava na morte. [...] Estava morto. Ressuscitaria?" (E.N.A.M., p. 141-142). A seguinte aparece logo na seqüência, incluindo-se a ressurreição do chefe peludo: "O Monge e o comandante morreram. Ressuscitariam mui breve. Os homens não acreditaram na sua morte." (E.N.A.M., p. 142). Já na última passagem a ausência da morte é reservada aos crentes: "Ele passara-se; não morrera... Ela não acreditava na morte. Morrem os incrédulos, os miseráveis, os peludos... Ele passou-se." (E.N.A.M., p. 157. Grifos meus, nas três citações).

O subtítulo - Romance dos tempos dos fanáticos do Contestado - também merece algumas considerações. A indicação da forma narrativa romance, cuja evocação suspende temporariamente as leis do mundo empírico e estabelece outras convenções, uma espécie de contrato entre o narrador e o leitor, válido enquanto durar a leitura, é relativizada quando acrescida desse moderador representado pela indicação de um tempo histórico definido e a respeito do qual já se cristalizaram algumas noções que adquiriram o estatuto de verdade. Esse tipo de relação com o referente externo parece ser uma particularidade de todo romance histórico, mais marcada ainda quando se indica, no título ou no subtítulo, o episódio ou o período que figura. O caminho escolhido pode ser o da subversão, da denúncia da escolha de uma versão como verdadeira, em detrimento de tantas possíveis. Não é o caso. O narrador confirma, parcialmente, a versão oficial ao empregar o termo fanáticos, aceitando a designação pejorativa. Entretanto, cria uma ambigüidade ao deixar uma brecha na construção. Contestado é uma referência direta à questão de limites, mas esta é apenas uma das facetas da revolta camponesa, eminentemente messiânica, embora denominada como Guerra do Contestado na história institucionalizada. 
Referir-se a fanáticos do Contestado pode ser entendido como fanáticos casualmente pertencentes à região, mas cuja dimensão não se reduz àquela questão. Ou seja, a cristalização não recebe um aval irrestrito. Note-se ainda que o "romance" não é "dos fanáticos", mas “dos tempos dos fanáticos", antecipando um aspecto do enredo.

A grande virtude da obra está, se não na identificação, que não chega a existir, pelo menos na compreensão do universo sertanejo, de um ponto de vista simpático. A posição do narrador tem muito eco da campanha do Diario da Tarde, "Pela humanidade!", sem dúvida lida pelo autor, o que fica claro na outra obra que publicou. A opção é caracterizar o mundo e o modo de vida das personagens, para que o leitor perceba as razões da existência de um clima propício à eclosão do movimento, clima que não surgiu de um momento para outro, resultado que foi de longo processo de maturação. $\mathrm{O}$ recurso usado é centrar a ação numa família que não morava nos redutos nem seguia José Maria mas, por acaso, encontrava-se no Irani em busca de cura quando se deu o ataque de João Gualberto e, por um equívoco, é tomada como contestadora dos poderes constituídos.

O tempo histórico recortado é de meados a fins de 1912, com flashbacks que retomam registros sobre o primeiro monge, portanto época anterior à metade do século precedente, e o período das primeiras posses às margens do rio Iguaçu, quando as disputas eram com as tribos indígenas, além de uma antecipação que alcança 1914, tempo mais aceso da "guerra santa", expressão que aparece a propósito dessa continuidade (E.N.A.M., p. 47). A representação do passado se dá nos diálogos entre as personagens, que contam, ao sabor das circunstâncias, passagens de sua vida e da de seus pais aos vizinhos, seus iguais, caracterizando-as concomitantemente ao espaço social, simulando absoluta naturalidade no processo de narrar os tempos pretéritos.

A situação ideal para a narrativa, como ensina Walter Benjamin em citadíssimo ensaio, ${ }^{4}$ cria-se durante a realização do trabalho artesanal em grupo. Vivendo num espaço em que predominavam as ocupações comunitárias, pouco permeável a experiências estranhas, os narradores caboclos tinham como temas as histórias familiares e as experiências diárias. Aquelas ligavam-nos às suas origens, garantindo-lhes raízes, um passado a relembrar. Estas apresentavam duas vertentes: o convívio com o maravilhoso e o cotidiano de trabalho árduo. O sobrenatural era um recurso com dupla função: responder a pergun-

4 BENJAMIN, Walter. O narrador. In: Magia e técnica, arte e política. Trad. por Sérgio Paulo Rouanet. 5. ed. São Paulo: Brasiliense, 1993. p. 197-221. 
tas sobre fenômenos naturais que a parca ciência de que dispunham não alcançava explicar, e tornar aceitáveis as duras condições de vida, quando não de morte, das quais não tinham como fugir. As conversas sobre o cotidiano constituíam um recurso didático, transmitindo a experiência de gestos e procedimentos que deveriam ser transmitidos milhares de vezes.

Observações desse teor são próprias dos discursos antropológico e sociológico. Ao estudo da ficção não interessa o que o universo contém, mas como é figurado esse conteúdo. Estas considerações se fizeram a partir do comentário sobre o uso de diálogos no texto, diretos ou indiretos. É justamente na representação da história e do modo de vida da região que Marés de Souza demonstra qualidades de ficcionista. Sua proposta não é relatar a Campanha do Contestado, mas a constituição do grupo social que, instalado naquele espaço temporal e geográfico, foi capaz de criar tal convulsão, ou melhor, foi levado a criá-la, no confronto com a força da civilização.

Os protagonistas, uma família de sitiantes, não são escolhidos por qualquer traço extraordinário, mas justamente em função de sua normalidade, de sua tipicidade. Como tantos outros moradores da região, eram herdeiros de posse, isto é, estavam fixados em terras das quais seus ancestrais haviam tomado posse, mas não dispunham de documentação legal. Viviam rusticamente, mas em relativa abastança, tementes a Deus e fiéis aos santos de sua devoção, enfrentando dura labuta, sobretudo na exploração da erva-mate. Era preciso muita firmeza para não ceder às imposições do progresso, resistindo às ofertas de compra de suas terras, operação que os transformaria, num primeiro estágio, em empregados dos novos proprietários, enquanto houvesse madeira a extrair, e logo em párias sociais. Nesse sentido, Eles não acreditavam na morte é um romance regionalista, atendendo de perto aos limites percebidos por Lúcia Miguel-Pereira:

só the pertencem [ao regionalismo] de pleno direito as obras cujo fim primordial for a fixação de tipos, costumes e linguagem locais, cujo conteúdo perderia a significação sem esses elementos exteriores, e que se passem em ambientes onde os hábitos e estilos de vida se diferenciem dos que imprime a civilização niveladora. ${ }^{5}$

5 MIGUEL-PEREIRA, Lúcia. Regionalismo. In: Prosa de ficção: de 1870 a 1920. Belo Horizonte: Itatiaia; São Paulo: Editora da Universidade de São Paulo, 1988 (Reconquista do Brasil. 2. série, v. 131). p. 175. 
O romance é estruturado em cinco partes - "O trabalho e a folga", "A doença", "A crença", "A luta" e "A fuga" - cada uma com um número variável de capítulos, entre quatro e oito, eventualmente trazendo epígrafes, que vão de citações bíblicas a trovas populares, passando por escritores de dimensão universal, nacional ou local, todas passíveis de relacionamento com a condição do sertanejo. $O$ autor não poupa epígrafes. Só as de abertura são três: M. B. Lourenço Filho comenta a insignificância do homem, Rostand refere-se ao possível caráter de verdade do sonho e Emiliano Pernetta enaltece o valor da oração. As diretrizes filosófico-existenciais do ângulo de abordagem do assunto são antecipadas por essas citações, que marcam uma dimensão nacional, alcançando a ocidental, para voltar ao plano regional, o ponto forte de Marés de Souza, ainda que anacrônico enquanto realização.

Vale frisar que, no comentário acima transcrito, Lúcia Miguel-Pereira tinha como baliza final o ano de 1920. Dois anos depois da publicação de Grande sertão: veredas, em pleno período de super-regionalismo, segundo termo que se tornou corrente, cunhado por Antonio Candido para designar a superação dos modelos que imperaram até os anos 30 , do ponto de vista estético não se justifica uma prática regionalista que remonta aos cânones da virada do século. Mas a escala que se está considerando aqui é outra. Por mais que a leitura das obras-primas seja gratificante, é preciso que alguém se disponha também a vasculhar a produção provinciana, quer para delinear a história da literatura, quer para dimensionar um conjunto de textos sobre um tema especifico, avaliando-lhe o significado e o papel na história de uma cultura.

A fratura do discurso de textos regionalistas, como o que ora se comenta, acontece quando o discurso erudito e o discurso do universo representado aparecem como camadas superpostas, passíveis de separação a qualquer momento. Em Eles não acreditavam na morte, o narrador demonstra intimidade com o cotidiano e com os hábitos de suas personagens, inclusive os hábitos lingüísticos, conseguindo um razoável rendimento da exploração da oralidade, mas inadvertidamente deixa aflorar o discurso em que transparece sem disfarces a voz do civilizado, ainda mais, do erudito, seja em eventuais vocábulos ou expressões, seja em explanações de caráter político-social.

A flutuação no plano lingüístico é reflexo da flutuação no plano ideológico. O narrador demonstra toda simpatia, ainda que sempre numa atitude paternalista, pelos crentes e pelos primeiros monges. João Maria é a lembrança de um peregrino dos tempos antigos que só praticava o bem, hoje um retrato no altar, entre as imagens dos santos católicos. Mas, em relação a José Maria, prefere manter uma posição de suposta imparcialidade, que se invalida e se denuncia como ajuizadora diante da posição de simpatia pelo sertanejo. A 
expressão da desconfiança para com o monge-curandeiro fica por conta do primo que acompanha a família da doente, objeto da paixão do rapaz. $O$ desconfiado primo descobre intenções lúbricas no olhar e nos gestos do líder, cujo procedimento era incontestável para todos os demais sertanejos que estão no povoado e, em conversas, narram as peripécias da trajetória do novo milagreiro, denominado "profeta", "mestre", "beato" e "taumaturgo". As duas primeiras designações podiam ser correntes, quanto à terceira já é duvidoso que acontecesse no meio sulino, $\mathrm{c}$ a última é francamente estranha àquele ambiente. Para os crentes, ele era "o compadre", ou ainda "seu Maria", opção muito a propósito para facilitar a identificação com João Maria, o de grata memória. $O$ narrador não oferece essa leitura para a supressão do primeiro nome de modo direto, mas fica a sugestão. Atribuir sempre aos outros a narração da história do mentor do grupo pode ser uma marca de modéstia, mas pode também ser um recurso para deixar proliferarem as lendas, de modo a aumentar seu prestígio. Também essa sugestão fica em aberto.

Não se pode deixar passar sem comentários a continuação do fio narrativo do enamorado ciumento, talvez a maior ousadia ficcional do autor $\mathrm{e}$ um bom mote para a discussão sobre a verdade ficcional. $O$ relato da morte do monge aparece no texto por três vezes. Na primeira não se lançam dúvidas sobre sua honestidade, nem sombras sobre sua grandeza. A leitura vale não só para conferir essa posição do narrador, como para observar a conjugação de fatos históricos e ficcionais:

De repente, oculto na cortina asfixiante de pólvora, Delfino Pontes, um dos comandantes de briga, correu em socorro de um irmão que rolava ensangüentado do cavalo. Quem será? Poucos perceberam. Era o Chefe. Era seu Maria, o compadre. Tombara como qualquer mortal, sem usar o ferro, pois, sequer carregara a velha espada que lhe presenteara o Coronel Henrique Paes de Almeida para defender-se do seu inimigo Coronel Francisco Ferreira de Albuquerque. Nos últimos momentos José Maria avançava por avançar, alheiado, resignado, como um louco, à espera dos reforços de São Sebastião. Fora levado na carga de seus cavalarianos. Suicídio? Não. Sinceramente acreditava $\mathrm{cm}$ suas palavras, julgando-se imortal. Confiava realmente no auxílio divino.

[...]

A indiferença com que marchou ao encontro da morte impressiona. Ele o senhor absoluto daquelas almas simples. 
Ele não acreditava na morte. Seu rosto tornara-se lívido. Quis falar. Ninguém compreendeu sua última mensagem. Da boca descia uma golfada contínua de sangue, do peito outra. As faces tornaram-se rubras, estranhas, diabólicas. Ficou irreconhecível. Deitou um último olhar para o céu nublado onde punha suas esperanças. Nada. Mirou por instantes a copada dos pinheiros. Estava morto. Ressuscitaria? Esperavam os crentes a realização dessa profecia. (E.N.A.M., p. 141-142)

No bloco seguinte o foco ilumina a força estadual, com o Comandante já morto. A escolha de um verbo lança alguma dúvida sobre o procedimento de José Maria, ainda que se refira ao outro chefe:

A peleia prosseguiu em duelo terrivel. Os milicianos, morto o Comandante, desarvoraram-se. Veio a debandada dos sobreviventes da luta inglória. O Faxinal de São João do lrani juncouse de cadáveres de pessoas e animais, rolados pelo chão humilde, resvalados pelo taimbé, caídos no banhado grande, chamado mesmo Banhado Grande. Mortos e feridos em quase igual número de parte a parte. A polícia debandou. Abandonou no campo fatídico da luta: armas, muniçōes, metralhadora, animais e mortos. Brilhante arsenal na mão de um adversário sagaz e atrevido.

Um desastre! Uma terrível desgraça! como profetizou o Comandante que não blazonava de ser profeta. (E.N.A.M., p. 142)

A última frase parece conter uma comparação elíptica. Se o Comandante "não blazonava", quer dizer que o monge sim? A carga semântica do verbo não fica despercebida. Páginas adiante o Comandante vai receber um adjetivo que não condiz com a condição de militar, embora sua força esteja amainada por outro adjetivo que é uma das virtudes castrenses mais celebradas: "bravo e afoito comandante". (E.N.A.M., p. 147)

No segundo registro da morte do líder, no bloco seguinte ao acima transcrito, os dois chefes são reunidos na morte, como em tantos outros textos:

- Conheceu papudo! - gritou Delfino ao descerrar o golpe de misericórdia na cabeça do Coronel João Gualberto, abrindoIhe o frontal. 
- Conheceu papudo! - disse o sargento Virgílio ao deitar por terra de seu cavalo branco o monge José Maria.

Isto foi o Irani. O Monge e o comandante morreram. Ressuscitariam mui breve. Os homens não acreditaram na sua morte. (E.N.A.M., p. 142)

A partir desse momento domina o plano ficcional, como dominara no início. Os episódios históricos factuais concentram-se sobretudo nessa passagem. No dificultoso retorno à casa, as personagens são transformadas em perigosas pela voz dos outros, e são obrigadas a agir como se o fossem. $O$ narrador não poupa apelos ao sentimentalismo, em cenas que beiram o patético, ultrapassando eventualmente suas fronteiras.

No último relato sobre a morte do monge, a novidade está na narração na voz do Otelo sertanejo. Já muito próximo ao desfecho, o rapaz, pouco antes de ser preso e morto pelos vaqueanos do coronel Fabrício, mesclando personagens históricas e ficcionais, faz um relato à amada, adquirindo a face dramática que nem a luta nem a fuga lhe proporcionara:

- Eu matei seu José Maria! Matei o esconjurado! Pra ele não se envolver mais com as famílias alheias, $e$ andar fingindo de santo. Não me iludi, não. A mim ele não enganou.

[...]

[1..] Eu na hora da briga, bombeava de cima de uma japecanga, quando vi seu José Maria, chapelāo de palha, fita branca no chapéu, entre os cavaleiros de São Sebastiāo, no meio da nuvem de fumaça. De lá do alto, atirei bem no coração do bruto. Disparei a arma. Ele caiu. $O$ outro tiro nāo sei quem deu. $O$ que matou, juro, foi o meu. Custoso errar o alvo naquela distância, coisa de seis passos... atirando de cima para baixo...

- Incrivel, Geraldo! Não acredito! Quem matou de pontaria o seu José Maria foi o Sargento Virgílio Rosa. Derrubou o santo do cavalo branco. Foi ele quem matou. Você conta de outro jeito... seja. (E.N.A.M., p. 172)

Se, para o historiador, não há documento capaz de comprovar se foi João Gualberto quem matou o monge, se o sargento que o acompanhava, no romance abre-se mais uma possibilidade, tão plausível como qualquer outra. Ainda que a interlocutora do diálogo lembre o atirador que consta na primeira versão, vale notar que naquela passagem faz-se referência a derrubar do cavalo, 
não a matar. O narrador deixa a decisão por conta do leitor. Mais incongruente não será o fato de a personagem, que não podia conhecer ninguém da tropa, saber não só o posto, mas até o nome do responsável pela morte do líder?

Em procedimentos insólitos como o último apontado reside a principal limitação de Eles não acreditavam na morte. Marés de Souza conhece o espaço social figurado, demonstra consciência da necessidade de romper com o sectarismo que dominava a abordagem histórica, mas a boa realização estética depende de um poder transfigurador que o texto não alcança. $O$ autor não é um pós-estruturalista ou pós-moderno avant la lettre, não é um precursor dos métodos históricos que só serão conhecidos no Brasil a partir da década de 70 e divulgados nos anos 80 . Entretanto, a obra merece algum entusiasmo, quer pela condição de inaugural, quer por certas opções de abordagem do histórico via ficcional, opçōes que só agora, quando as teorias das aproximações e das singularidades dos discursos histórico e ficcional tanto se sofisticou, é possível perceber como diferenciadas em sua época.

\section{RESUMO}

Estudo do primeiro texto ficcional que foi escrito sobre o movimento messiânico conhecido como Contestado, Eles não acreditavam na morte, do paranaense Frederecindo Marés de Souza, buscando, independentemente de suas limitações do ponto de vista estético, as particularidades no estabelecimento do diálogo do discurso histórico com o ficcional.

Palavras-chave: romance histórico, Contestado, literatura no Paraná.

\section{RÉSUMÉ}

Cet étude aborde le premier texte de fiction, en considerant l'époque de l'écriture, qui a eu comme sujet le mouvement méssianique appelé Contestado - Eles não acreditavam na morte, de Frederecindo Marés de Souza - en essayant d'apercevoir, au-delà des limitations esthétiques, les particularités du dialogue du discours historique et le discours fictionnel.

Mots-clé: roman historique, Contestado, littérature au Paraná. 


\section{REFERÊNCIAS BIBLIOGRÁFICAS}

BENJAMIN, Walter. Magia e técnica, arte e política. Trad. por Sérgio Paulo Rouanet. 5. ed. São Paulo: Brasiliense, 1993 (Obras escolhidas, 1).

MIGUEL-PEREIRA, Lúcia. Prosa de fição: de 1870 a 1920. [s/ed.] Belo Horizonte: Itatiaia; São Paulo: Editora da Universidade de São Paulo, 1988.

MONTEIRO, Duglas Teixeira. Errantes do novo século: um estudo sobre o surto milenarista do Contestado. São Paulo: Duas Cidades, 1974.

. Um confronto entre Juazeiro, Canudos e Contestado. In: FAUSTO, Boris (Dir.) História Geral da Civilização Brasileira. O Brasil Republicano (Sociedades e instituições - 1889-1930). Rio de Janeiro; São Paulo: Difel, 1977. t. 3, v. 2

NASCIMENTO, Noel. Casa Verde. São Paulo: Martins, 1963. 2. ed. Curitiba: BeijaFlor, 1981. 3. ed. Curitiba: Lítero-Técnica, 1985.

OLIVEIRA NETO, Godofredo. O Bruxo do Contestado. Rio de Janeiro: Nova Fronteira, 1996.

QUEIROZ, Maria Isaura Pereira de. Guerre Sainte au Brésil: le mouvement messianique du Contestado. Boletim da Faculdade de Filosofia, Ciências e Letras, São Paulo, n. $187,1957$.

O messianismo: no Brasil e no mundo. São Paulo: Editora da Universidade de São Paulo; Dominus, 1965.

QUEIROZ, Maurício Vinhas de. Messianismo e conflito social: a guerra sertaneja do Contestado - 1912-1916. Rio de Janciro: Civilização Brasileira, 1966. 3. ed. São Paulo: Ática, 1981.

SCHÜLLER, Donaldo. Império caboclo. Florianópolis: Ed. da UFSC; FCC Ed.; Porto Alegre: Movimento, 1994.

SASSI, Guido Wilmar. Geração do deserto. Rio de Janeiro: Civilização Brasileira, 1964. 2. ed. Porto Alegre: Movimento, 1982.

SILVA, Alcides Ribeiro J. da. Os rebeldes brotam da terra. São Paulo: FTD, 1995.

SOUZA, Frederecindo Marés de. Eles não acreditavam na morte. Curitiba: Instituto Histórico, Geográfico e Etnográfico Paranaense, 1978.

O presidente Carlos Cavalcanti e a revolta do Contestado. Curitiba: LíteroTécnica, 1987 (Estante Paranista, 29). 